\title{
Is Prophylactic Lumbar Discectomy Ever Indicated?
}

\author{
Fred L. Cohen, William J. Murphy, Mark Bernstein
}

Can J Neurol Sci. 2011; 38: 375-378

With the wide availability of non-invasive imaging techniques, the occurrence of a patient with a large disc herniation who ultimately has complete disappearance of the herniation on imaging without surgery is not rare. ${ }^{1-4}$ It is unclear how common this is, as most patients who recover from sciatica do not get repeat imaging. Alternatively, how commonly cauda equina syndrome subsequently occurs in patients with improving sciatica and/or asymptomatic lumbar disc herniations is not clearly known.

Questions about the role of prophylactic lumbar discectomy have not been explored, and if performed by surgeons, have not been reported in the literature. But they are very relevant due to the frequency of lumbar disc disease and within the context of other prophylactic surgeries including appendectomy, colectomy, cholecystectomy, oophorectomy, thyroidectomy, mastectomy, aortic aneurysm repair, and in the realm of the neurosurgeon carotid endarterectomy and intracranial aneurysm repair.

\section{Illustrative case}

In the spring of 2001, a 59-year-old retired aeronautical engineer bent over and experienced acute severe low back pain radiating to the right hip and leg. He began flexion-distraction treatment with a chiropractor, made good clinical progress and two months later was subjectively improved. On examination the right ankle reflex was absent, straight leg raising was normal bilaterally, he had limited ability to bend forward, but motor and sensory examinations were normal. Magnetic resonance imaging (MRI) showed a large disc herniation (Figure 1). The patient was seen in his home city but lived most of the year in the far north and flew his own small plane. The location where he lived was very remote with small airplane transportation subject to frequent impassable weather conditions at any time. The possibility of cauda equina syndrome and the implications of a permanent neurological deficit were discussed with him. Surgery was offered but he declined.

In early 2007 , he returned for chiropractic care for some nonspecific complaints. He was having no low back symptoms and the right ankle reflex remained absent. A repeat lumbar MRI was obtained and showed virtually complete resolution of the disc herniation (Figure 2).

\section{DISCUSSION}

This case illustrates that large lumbar disc herniations can resolve without any invasive treatment, including surgery. There are a number of reports that describe this phenomenon. ${ }^{1-4}$ Proposed mechanisms include: 1) retraction into the inter- vertebral space; 2) dehydration/shrinkage; and 3) resorption due to inflammatory reaction. ${ }^{1-4}$

However, because of this patient's prolonged voluntary isolation from ready access to surgical care, if cauda equina syndrome were to develope he would run the risk of not obtaining surgical treatment until well after the optimal time window had passed, which is 48 hours based on a meta-analysis of the literature. ${ }^{5}$ Thus, one can reasonably pose the question: "Was this asymptomatic patient with a documented disc herniation a candidate for prophylactic discectomy?" The question of prophylactic discectomy has never been addressed before to our knowledge although one retrospective series in pet animals demonstrated safety and efficacy of the procedure. ${ }^{6}$ Furthermore, there are analogous situations in other specialties and other disease processes in which the issue of prophylactic surgery has been considered and adopted.

Mastectomy, colectomy, oophrectomy, cholecystectomy, thyroidectomy, appendectomy, aortic aneurysm repair, intracranial aneurysm clipping, and carotid endarterectomy have all, at one time or another, been performed as prophylactic operations, and each of these procedures has some defined but still controversial indications. ${ }^{7-17}$ Women with abnormal or mutated BRCA1 (on chromosome 17q21) or BCRA2 (on chromosome 13q12-q13) genes have an estimated lifetime risk of developing breast cancer between $56 \%$ and $90 \%$, resulting in adoption of prophylactic mastectomy starting around $1980 .^{13,14}$

Prophylactic appendectomy has long been considered for patients undergoing abdominal surgery for other indications. ${ }^{11}$ More recently appendectomy has been recommended in situations where the patient is going to be in a remote medical care environment. Australia requires its physicians wintering in Antarctic research stations to undergo prophylactic appendectomy. ${ }^{18}$ So, more intermittently, have Russia, Chile, Argentina, France, and the United Kingdom. ${ }^{19}$ Similar concerns have been applied to spaceflight and submarine travel. ${ }^{20,21}$

Prophylactic oophrectomy has not only been advocated for women at high risk for developing ovarian cancer, but even as a

\footnotetext{
From Neurosurgery (FLC), Palm Beach Gardens; Gary Roberts \& Associates (FLC),

West Palm Beach; Chiropractic (WJM), Jupiter, Florida, U.S.A.; Division of Neurosurgery (MB), University of Toronto, Toronto, Ontario, Canada.

Received August 16, 2010. Final Revisions Submitted September 30, 2010. Correspondence to: Mark Bernstein, Division of Neurosurgery, Toronto Western Hospital, University Health Network, 4 West, 399 Bathurst Street, Toronto, ON, M5T 2S8, Canada.
} 

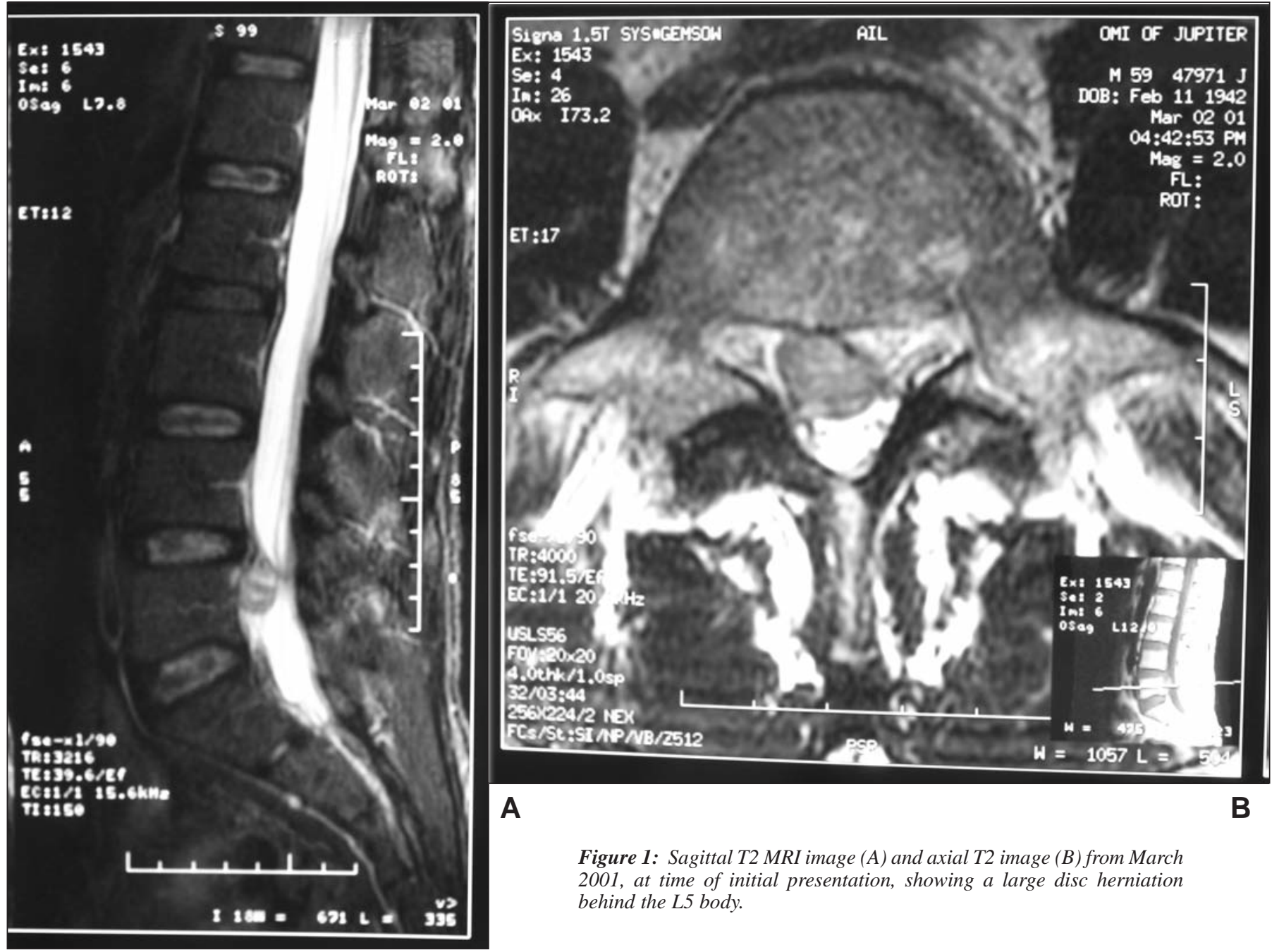

Figure 1: Sagittal T2 MRI image (A) and axial T2 image (B) from March 2001, at time of initial presentation, showing a large disc herniation behind the L5 body.

prevention for those at high risk for breast cancer. ${ }^{13}$ Colectomy has been advocated in patients with familial adenomatous polyposis (FAP) (germline mutation on the APC gene) and with hereditary nonpolyposis colorectal cancer (HNPCC - a noncancerous condition identified by a positive family history for non-FAP-related colorectal cancer and a genetic mutation in a mismatch repair gene, hMSH2, hMLH1, or HMSH6) ${ }^{10,16}$, and even in some cases of chronic ulcerative colitis with dysplasia. The goal is to reduce the occurrence of colon cancer, which has a high incidence in individuals with these pre-malignant conditions.

Prophylactic cholecystectomy has been advocated for patients below the age of 50 with demonstrated asymptomatic gallstones, and in patients of any age with associated diabetes. ${ }^{12}$ Prophylactic total thyroidectomy is being studied in the prevention of medullary thyroid carcinoma in patients age 19 or younger and asymptomatic with a history of multiple endocrine neoplasia (MEN, type 2A, with a mutated allele of the RET proto-oncogene). ${ }^{15}$ Aortic root replacement has been used to "prevent aortic catastrophe" in Marfan patients", and carotid endarterectomy was used routinely up to the 1980 s to prevent stroke in patients with asymptomatic carotid stenosis until data from trials decreased this practice ${ }^{8}$. Surgery to clip unruptured intracranial aneurysms has been widely used on a per case basis, has been deemed to be a reasonable treatment option, and the quality of life of such patients has been studied. ${ }^{17}$

While none of these prophylactic procedures is without controversy, and none is standard practice, this is far from the landscape one finds in searching for discussions on prophylactic spinal surgery. One reason for this may be that cauda equina syndrome negatively impacts quality of life but is not lifethreatening as is cancer, ruptured aorta, and stroke. Certain of these prophylactic operations are more analogous to the herniated disc situation than others. A herniated disc does not constitute an expectancy of future disease in that it has already established itself as a pathologic condition relative to the normal spinal anatomy. In that sense it is more like the gallbladder and intracranial aneurysm situation in which the presence of stones or the aneurysm respectively define a pathologic condition already in existence. This is somewhat different from thyro- 
idectomy or appendectomy surgery in which, at the time of operation, there is no definable or discoverable abnormal tissue or pathologic entity verifiable, just a statistical expectancy of a future diseased state.

The dilemma about the role of prophylactic discectomy is amplified by the lack of hard data on the incidence of complete resolution of a disc herniation and conversely the incidence of future cauda equina syndrome once a disc has ruptured. The stroke rate from asymptomatic carotid stenosis has been studied as has the annual rupture rate for asymptomatic intracranial aneurysms, but such data are not so readily available for lumbar disc disease. We do know that the vast majority of patients recover from their first episode of sciatica with conservative management, but how many of these patients go on to further episodes of sciatica or to develope cauda equina syndrome has not been well studied. We also know that surgery for sciatica from disc rupture speeds up recovery but its salutory effects may diminish over time..$^{22,23}$

Regarding the incidence of cauda equina syndrome, most articles describe it as a rare or unusual complication of disc herniation. Kostuik cites an incidence between 2.2 and 3.2 percent following lumbar disc herniation. ${ }^{24}$ Small et al approximate the incidence in the low back pain population as 4 in 10,000 or $0.04 \% .{ }^{25}$ Proper longitudinal studies have not been done so the exact incidence is not known.

There is even less information available on how often a significant lumbar disc herniation regresses spontaneously. While most consider it rare, Splendiani and coworkers did a prospective study of 64 patients while trying to define predictive criteria in disc resolution and found that $100 \%$ of free-fragment lumbar disc herniations regressed on $\mathrm{MRI}^{4}$. This is a remarkable finding, if it is reproducible by others. Another study suggests an incidence of about $10 \% .^{2}$ Making such a determination accurately would require regular MRI follow-up over several years of large numbers of patients treated conservatively for known disc protrusions, an easy study to do. As for surgeons' views on this issue, a qualitative survey study would help assess neurosurgeons' and orthopedic spine surgeons' willingness to consider prophylactic discectomy as an option for selected patients. Some surgeons may have never considered this option and others may have done so, perhaps stimulated by a patient's request.

In order for prophylactic discectomy to be a justifiable and sensible option to present to patients, the risk of development of cauda equina syndrome and/or intractable sciatica (i.e. lifealtering disability due to the disc disease) in an asymptomatic patient with a known disc herniation, would have to be greater than the risk of lumbar discectomy. The temporary and/or minor risks of lumbar discectomy such as cerebrospinal fluid leak, urinary retention, and minor nerve root dysfunction range up to $5 \%$ in contemporary series. ${ }^{26}$ The risk of life-altering complications such as vascular injury, discitis, pulmonary embolus, and complications of positioning is not widely reported but probably range around $1 \% .^{27-32}$

We respectfully suggest that prophylactic lumbar discectomy become the subject of debate, discussion, and study amongst neurosurgeons and orthopedic spine surgeons to fully explore the potential value (or lack thereof) of this therapeutic option. When compared to other prophylactic surgical procedures, due diligence has not been done for prophylactic discectomy.

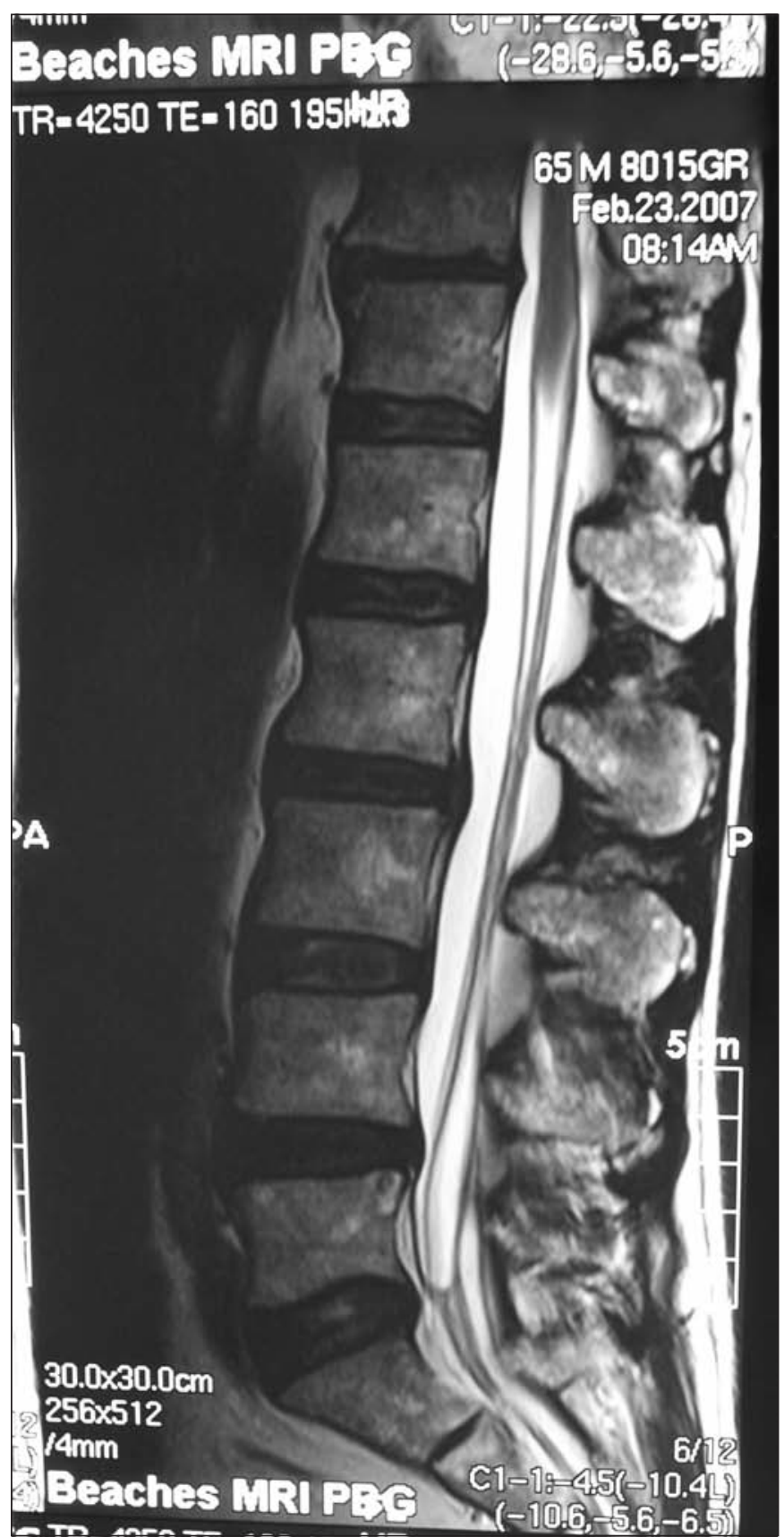

Figure 2: Sagittal T2 MRI image from February 2007 showing complete resolution of the herniated disc.

\section{REFERENCES}

1. Fager CA. Observations on spontaneous recovery from intervertebral disc herniation. Surg Neurol. 1994; 42:282-6.

2. Keskil S, Ayberk G, Evliyaoglu C, et al. Spontaneous resolution of protruded lumbar discs. Minim Invasive Neurosurg. 2004; 47: 226-9

3. Slavin KV, Raja A, Thornton J, et al. Spontaneous regression of a large lumbar disc herniation: report of an illustrative case. Surg Neurol. 2001; 56:333-6. 
4. Splendiani A, Puglielli E, DeAmicis R, et al. Spontaneous resolution of lumbar disk herniation: Predictive signs for prognostic evaluation. Neuroradiology. 2004; 46:916-22.

5. Ahn UM, Ahn NU, Buchowski JM, et al. Cauda equina syndrome secondary to lumbar disc herniation: a meta-analysis of surgical outcomes. Spine. 2000; 25:1515-22.

6. Bartels KE, Higbee RG, Bahr RJ, et al. Outcome of and complications associated with prophylactic percutaneous laser disk ablation in dogs with thoracolumbar disk disease: 277 cases (1992-2001). J Am Vet Med Assoc. 2003; 222:1733-9.

7. Arazi HC, Capparelli FJ, Linetzky B, et al. Carotid endarterectomy in asymptomatic carotid stenosis: a decision analysis. Clin Neurol Neurosurg. 2008; 110:472-99.

8. Barnett HJ, Meldrum HE, Eliasziw M. North American Symptomatic Carotid Endarterectomy Trial (NASCET) collaborators: the appropriate use of carotid endarterectomy. Can Med Ass J. 2002; 166:1169-79.

9. Cameron DE, Alejo DE, Patel ND, et al. Aortic root replacement in 372 Marfan patients: evolution of operative repair over 30 years. Ann Thorac Surg. 2009; 87:1344-9.

10. Church JM, Fazio VW, Lavery IC, et al. Quality of life after prophylactic colectomy and ileorectal anastamosis in patients with familial adenomatous polyposis. Dis Colon Rectum. 1996; 39:1404-8.

11. Fisher KS, Ross DS. Guidelines for therapeutic decision in incidental appendectomy. Surg Gynecol Obstet. 1990; 171:95-8.

12. Friedman LS, Roberts MS, Brett AS, et al. Management of asymptomatic gallstones in the diabetic patient. A decision analysis. Ann Intern Med. 1989; 110:1033-4.

13. Metcalfe KA. Oophorectomy for breast cancer prevention in women with BRCA1 or BRCA2 mutations. Womens Health. 2009; 5:63-8.

14. Rebbeck TR, Friebel T, Lynch HT, et al. Bilateral prophylactic mastectomy reduces breast cancer risk in BRAC1 and BRAC2 mutation carriers: the PROSE Study Group. J Clin Oncol. 2004; 22:1055-62.

15. Skinner MA, Moley JA, Dilley WG, et al. Prophylactic thyroidectomy in multiple endocrine neoplasia Type 2A. N Engl J Med. 2005; 353:1105-13.

16. Syngal S, Weeks JC, Schrag D, et al. Benefits of colonoscopic surveillance and prophylactic colectomy in patients with hereditary nonpolyposis colorectal cancer mutations. Ann Int Med. 1998; 129:787-96.

17. Yamashiro S, Nishi T, Koga K, et al. Postoperative quality of life of patients treated for asymptomatic unruptured intracranial aneurysms. J Neurosurg. 2007; 107:1086-91.
18. Lugg DJ. Antarctic medicine. JAMA. 2000; 283:2082-4

19. Campbell MR, Johnston SL, Marshburn T, et al. Nonoperative treatment of suspected appendicitis in remote medical care environments: Implications for future spaceflight medical care. J Am Coll Surg. 2004; 198:822-30.

20. Ball J, Evans CH. Institute of Medicine. Safe passage: Astronaut care for exploration missions. National Academy Press; Washington DC: 2001.p. 127.

21. Lugg, D. Medicine for Mars. Autumn 2005. Issue 8. Available from: www.aad.gov.au/Asset/magazine/2005autumn/22\%20medicine $\% 20$ for\%20Mars.pdf

22. Atlas SJ, Keller RB, Wu YA, et al. Long-term outcomes of surgical and nonsurgical management of sciatica secondary to a lumbar disc herniation: 10 year results from the Maine lumbar spine study. Spine. 2005; 30:927-35

23. Paul WC, Arts MP, Brand R, et al. Timing of surgery for sciatica: subgroup analysis alongside a randomized trial. Eur Spine J. 2009; 18:538-45

24. Kostuik JP. Medicolegal consequences of cauda equina syndrome: an overview. Neurosurg Focus. 2004; 16:e8.

25. Small SA, Perron AD, Brady WJ. Orthopedic pitfalls: cauda equina syndrome. Am J Emerg Med. 2005; 23:159-63.

26. Fallah A, Massicotte EM, Fehlings MG, et al. Admission and acute complication rate of outpatient lumbar microdiscectomy. Can J Neurol Sci. 2010; 37:49-53.

27. Ahn Y, Kim JU, Lee BH, et al. Postoperative retroperitoneal hematoma following transformainal percutaneous endoscopic lumbar discectomy. J Neurosurg Spine. 2009; 10:595-602.

28. Dosoglu M, Is M, Pehlivan M, et al. Nightmare of lumbar disc surgery: iliac artery injury. Clin Neurol Neurosurg. 2006; 108: 174-7.

29. Gupta R, Batra S, Chandra R, et al. Compartment syndrome with acute renal failure: a rare complication of spinal surgery in the knee-chest position. Spine. 2008; 33:E272-3.

30. Kylanpaa-Back ML, Suominen RA, Salo SA, et al. Postoperative discitis: outcome and late magnetic resonance imaging evaluation of ten patients. Ann Chir Gynaecol. 1999; 88:61-4.

31. Ramirez LF, Thisted R. Complications and demographic characteristics of patients undergoing lumbar discectomy in community hospitals. Neurosurgery. 1989; 25:226-30.

32. Szolar DH, Preidler KW, Steiner H, et al. Vascular complications in lumbar disk surgery: report of four cases. Neuroradiology. 1996; 38:521-5. 